\title{
The Cost of Falls Among the Community-Dwelling Elderly
}

\author{
NORMAN V. CARROLL, PhD; PATRICIA W. SLATTUM, PharmD, PhD; and FRED M. COX, PhD
}

\begin{abstract}
OBJECTIVE: To estimate the direct medical costs of falls in the population of community-dwelling elderly.

METHODS: Data from a sample of 4,025 consumers from the 1997 Medical Expenditure Panel Survey were used to make estimates that were representative of the population of civilian, noninstitutionalized elderly in the United States.

RESULTS: In 1997, 9\% of the noninstitutionalized elderly population of the United States reported medical conditions related to falls. The estimated total direct medical cost of these conditions was $\$ 6.2$ billion in 1997 dollars and $\$ 7.8$ billion in 2002 dollars. The mean cost per person who had fallen was \$2,039 in 1997 dollars and \$2,591 in 2002 dollars. Inpatient hospitalizations accounted for $65 \%$ of total costs, followed by office-based medical visits and home health care, each accounting for about $10 \%$ of total direct medical costs, and hospital outpatient visits for $7.6 \%$. About $78 \%$ of fall-related costs were reimbursed by Medicare.

CONCLUSION: Fall-related medical conditions affect a substantial number of the community-dwelling elderly and result in direct medical costs of $\$ 6$ to $\$ 8$ billion per year in the United States. The total economic burden of falls is significantly higher because this estimate does not include direct nonmedical, intangible, and indirect costs. The results of this study highlight the importance of research aimed at decreasing the incidence and severity of falls in the elderly.
\end{abstract}

KEYWORDS: Falls, Elderly, Direct medical costs, MEPS

J Manag Care Pharm. 2005;11(4):307-16

\section{Authors}

NORMAN V. CARROLL, PhD, is a professor of pharmacy administration, and PATRICIA W. SLATTUM, PharmD, PhD, is an assistant professor of pharmacy and a geriatric specialist, Virginia Commonwealth University School of Pharmacy, Richmond, Virginia; FRED M. COX, PhD, is a director/team leader, Outcomes Research, Developmental Products, Pfizer, Inc., New York, New York.

AUTHOR CORRESPONDENCE: Norman V. Carroll, PhD, Professor of Pharmacy Administration, Virginia Commonwealth University School of Pharmacy, 410 North 12th St., Box 980533, Richmond, VA 23298-0533. Tel: (804) 828-2587; Fax: (804) 828-8359; E-mail: nvcarroll@vcu.edu

Copyright $\odot$ 2005, Academy of Managed Care Pharmacy. All rights reserved.
$\mathrm{F}$ alls are a major problem for the community-dwelling elderly. Approximately 30\% of this group experience a fall each year, some of which are not injurious. ${ }^{1-6}$ Many falls result in serious injury-injuries in which the patient requires medical attention or rehabilitation before resuming normal activities.

A review of the literature indicates rates of between 4 and 10 injurious falls per 100 elderly persons per year and between 2 and 5 fall-related fractures per 100 elderly persons per year. ${ }^{1,3,4,6,7}$ One authority estimates that $1 \%$ of elderly falls result in hip fractures. ${ }^{6}$ A hospital-based study found that $68 \%$ of elderly hospitalizations for injury were fall-related and that the percentage of injuries due to falls increases with increasing age: $86 \%$ of injuries to those older than 85 years were due to falls. ${ }^{8}$ Finally, falls have been identified as a strong predictor of institutionalization in a nursing home ${ }^{9}$ or death. ${ }^{10}$

Falls are particularly relevant to pharmacists because medication use has been associated with falling. Most falls result from an interaction between multiple factors. Consistently reported risk factors for falling include arthritis; depressive symptoms; orthostasis; impaired cognition, vision, balance, gait, or muscle strength; or use of 4 or more medications. ${ }^{11}$ As the number of risk factors increases, so does the risk of falling. ${ }^{3}$ Specific medications, particularly psychotropic drugs, have also been associated with an increased risk of falling. ${ }^{12}$

Interventions for the prevention of falls in the elderly have been reviewed previously. ${ }^{13-15}$ Since many factors contribute to the risk of falling, successful interventions employ multifactorial assessment and management strategies. Medications are a potentially modifiable risk factor for falling, so interventions often include a medication management component. ${ }^{11,14,16}$ The individual contribution of medication management to the overall success of multifactorial fall risk assessment and management interventions has not been documented. Because of the relationship between falls and pharmaceuticals, pharmacists are frequently involved in developing interventions to reduce fall risk. Pharmacists need accurate estimates of the costs of falls to assess the economic impact of these interventions.

On a broader level, government and managed care decision makers need accurate estimates of the cost of falls in the community-dwelling elderly to support cost-effectiveness and cost-benefit analyses of the most effective means of reducing falls and decreasing fall-related injury. Government decision makers need estimates to guide determination of funding priorities and policies. Pharmaceutical companies depend on accurate cost estimates to determine the economic feasibility of fall-related drug development and to estimate the cost- 
effectiveness of products. Without these estimates, they lack critical information needed to decide whether or not to initiate or continue the development of products designed to decrease the risks or complications of falling.

Given that falls result in substantial morbidity for the community-dwelling elderly, they likely result in significant economic costs. A number of studies suggest that this is true. However, the utility of these studies is limited because findings are based on samples drawn from small geographic areas, $4,8,17,19$ estimates are provided for only hospital-related ${ }^{8,19}$ or fracturerelated ${ }^{20,21}$ costs resulting from falls, and estimates are based on data that are 10 or more years old. , $^{417-19}$

The objective of this study was to provide a comprehensive estimate of the direct medical costs of fall-related injuries in a nationally rep resentative sample of community-dwelling elderly.

\section{Methods}

This study used a prevalence approach to estimate the costs of fall-related injury. Data for the study were taken from the 1997 Medical Expenditure Panel Survey (MEPS). MEPS is a household interview survey cosponsored by the Agency for Healthcare Research and Quality and the National Center for Health Statistics. Its purpose is to "provide nationally representative estimates of health care use, expenditures, sources of payment, and insurance coverage for the U.S. civilian, noninstitutionalized population." ${ }^{22}$ The MEPS collects self-reported information about consumers' demographic characteristics, health conditions, use of medical care services, and charges and payments for those services.

Two of the 4 major MEPS component surveys were used in this study: the Household Component (HC) and the Medical Provider Component (MPC). The HC consists of a series of in-person, household interviews with a nationally representative sample of the U.S. civilian, noninstitutionalized population. The MPC is a series of mail and telephone interviews with medical providers (hospitals; office-based providers such as physicians, chiropractors, psychologists, or optometrists; dentists; pharmacies; and home health care providers.) "The MPC supplements and validates information on medical care events reported in the MEPS Household Component.." ${ }^{23}$ The MPC is the primary source of provider payment information. ${ }^{24}$

The MEPS is conducted as a series of in-home, computerassisted personal interviews. Each respondent is interviewed 5 times over a $2^{1 / 2}$ year time frame to yield 2 calendar years of data. One part of each interview consists of the respondent's enumeration of medical conditions that he or she experienced since the last interview (or since the start date of January 1 , 1997, for the initial interview). The following series of questions is used for this purpose:

1. I'd like to talk about (person's) health.

2. We're interested in learning about health problems that may have bothered (person) between (start date) and (end date). Health problems include physical conditions, accidents, or injuries that affect any part of the body as well as mental or emotional health conditions, such as feeling sad, blue, or anxious about something. (For the initial interview, the start date is January 1, 1997, and the end date is the date of the interview. For subsequent interviews, the start date is the date of the previous interview, and the end date is the date of the current interview.)

3. Between (start date) and (end date), did (person) have any physical or mental health problems, accidents, or injuries? Please include all of (person's) conditions, accidents, or injuries regardless of whether (person) saw medical provider, received treatment, or took medications.

4. What did (person) have?

5. Did (person) have any other health problems, accidents, or injuries?

Interviewers record patients' descriptions of their medical conditions verbatim. These are later converted to ICD-9 (International Classification of Diseases, 9th Revision) codes by trained coders. If the respondent reported that he or she did have a medical condition, then the following question is asked for each condition reported.

6. Was (condition) due to an accident or injury? If so, the respondent is asked:

7. Did the accident or injury involve any of the things listed on this card? (One of the items on the card is "fall (exclude falls related to sports)." In this way, the MEPS specifically identifies medical conditions that result from falls.)

In a separate section of each interview, respondents are asked to recall all medical events they have experienced since the last interview (or since the start date for the initial interview). They are asked specifically and by means of separate questions to recall all hospitalizations, emergency room visits, visits to hospital outpatient departments, office-based visits (such as to physicians, chiropractors, psychologists, or optometrists), home health-care, dentist visits, and prescription drug purchases. Respondents are asked to refer to records they may have-such as receipts, checkbooks, or calendars-to help them recall medical events. As another aid to recall, respondents are provided with a printout of medical events that they reported in prior rounds of the MEPS.

The interviewer then asks respondents to identify the medical condition or conditions that led to or were treated at each medical event. In this way, the MEPS links all medical events to the medical conditions that caused them, and because medical conditions resulting from falls are specifically identified as such, it is possible to identify all medical events resulting from falls.

Respondents are also asked about the charges and payments for each medical event. These estimates are verified by charge and payment data supplied by providers through the MPC component of the MEPS survey.

MEPS data are published for each year that the survey is conducted. This study used data from 1997. Data are made 
available as a series of data files.

The Medical Conditions file provides self-report data about medical conditions (or health problems) experienced by respondents during the year. Each record describes a specific medical condition reported by a specific respondent. The file contains the 3-digit ICD-9 codes associated with treatments resulting from the medical condition, any 2-digit ICD-9 procedure codes resulting from the condition, and whether the respondent died or was institutionalized in a health care facility during the year. The Medical Conditions file also indicates whether or not the condition resulted from a fall. The Consolidated Full Year file is a person-level file that provides demographic information for each respondent.

There is also a series of 7 medical event files that provide detailed information on utilization, charges, and reimbursement for inpatient hospitalizations, emergency room care, outpatient hospital services, office-based provider services, home health care, dental services, and prescription drug use. A medical event is a specific patient's use of a specific medical service at a specific time. Each medical event file includes information on charges and actual reimbursements for each medical event. All files can be linked by unique combinations of patient, event, and condition identifiers.

Data were prepared for final analysis in 2 stages. First, the Medical Conditions and Consolidated Full Year files were linked and analyzed to identify elderly respondents (those aged 65 years or older) who reported a fall-related medical condition. The second stage of analysis linked the file of the elderly person who had fallen (faller) to each of the 7 medical event files. This resulted in a Final Analysis file that included demographic characteristics, fall-related health care utilization, and fall-related health care expenditure information for elderly fallers.

Figure 1 illustrates more fully the development of the analysis file. This file was analyzed to estimate the direct medical costs of fall-related medical conditions in the community-dwelling elderly population for 1997. Because this was a prevalence study, fall-related costs included costs that were incurred in 1997 but resulted from falls in previous years. The study did not include costs that were incurred after 1997 for falls that occurred in 1997. So, the study included only fall-related costs incurred in 1997.

MEPS reports both the amount providers were actually reimbursed for services provided and the amounts providers charged for those services. For all services except dental and prescription drugs, charges were substantially higher than actual reimbursements. Cost estimates in this study are based on actual reimbursements, not charges.

MEPS data provide sample weights for each respondent. Use of these weights allows the researcher to produce estimates that accurately re present the civilian noninstitutionalized population in the United States. The total costs of fall-related care were calculated as the weighted sum of costs for all fall-related
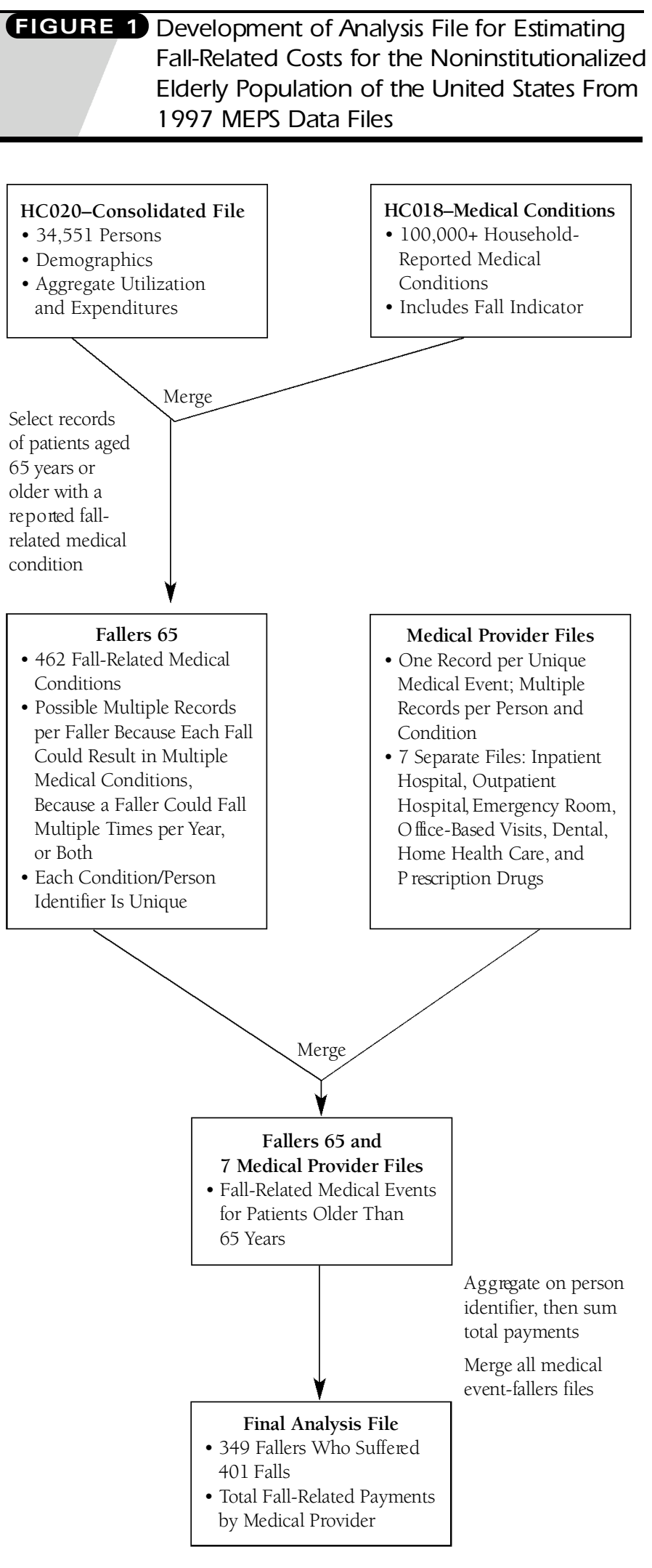
TABLE 1$)$ Costs and Utilization of Fall-Related Medical Care for the Noninstitutionalized Elderly Population of the United States in 1997*

\begin{tabular}{|c|c|c|c|c|c|c|}
\hline \multirow[b]{2}{*}{ Medical Event } & \multirow{2}{*}{$\begin{array}{c}\text { No. of Fallers } \\
\text { Receiving Treatment } \dagger, \ddagger\end{array}$} & \multirow{2}{*}{$\begin{array}{c}\text { No. of } \\
\text { Falls Treated }\end{array}$} & \multicolumn{4}{|c|}{ Total Costs $(\$)$} \\
\hline & & & Physician & Facility & (1997 Dollars) & (2002 Dollars)§ \\
\hline Emergency room visits & $\begin{array}{r}805,318 \\
(97)\end{array}$ & $\begin{array}{r}809,983 \\
(98)\end{array}$ & $48,788,296$ & $327,797,879$ & $376,586,175$ & $497,470,337$ \\
\hline Inpatient hospitalizations & $\begin{array}{r}381,624 \\
(48)\end{array}$ & $\begin{array}{r}383,693 \\
(49)\end{array}$ & $350,558,973$ & $3,226,660,912$ & $3,577,219,885$ & $4,725,507,468$ \\
\hline Home health care & $\begin{array}{r}315,122 \\
(49)\end{array}$ & $\begin{array}{r}318,939 \\
(50)\end{array}$ & & & $972,683,169$ & $1,146,793,456$ \\
\hline Office-based visits & $\begin{array}{r}1,665,054 \\
(191)\end{array}$ & $\begin{array}{r}1,782,227 \\
(206)\end{array}$ & & & $643,522,435$ & $758,712,951$ \\
\hline Dental visits & $\begin{array}{r}29,555^{\|} \\
(4)^{\|}\end{array}$ & $\begin{array}{r}29,555^{\|} \\
(4)^{\|}\end{array}$ & & & $44,824,538$ & $52,848,130$ \\
\hline Outpatient visits & $\begin{array}{r}307,320 \\
(39)\end{array}$ & $\begin{array}{r}307,320 \\
(39)\end{array}$ & $143,392,783$ & $345,562,796$ & $488,955,579$ & $576,478,628$ \\
\hline Prescription drugs & $\begin{array}{r}1,033,482 \\
(118)\end{array}$ & $\begin{array}{r}1,047,801 \\
(121)\end{array}$ & & & $70,865,937$ & $89,999,740$ \\
\hline Total & $2,406,641$ & & & & $6,174,657,718$ & $7,847,810,710$ \\
\hline \multicolumn{7}{|c|}{$\begin{array}{l}\text { \# The total number of medical events amounts to more than 2,406,641 because each faller could experience multiple medical events per fall and multiple falls during the year. } \\
\S \text { Estimates were converted to } 2002 \text { dollars by multiplying each estimate by the increase in the appropriate Consumer Price Index percentage change from } 1997 \text { to } 2002 . \\
\text { We used the Consumer Price Index for Hospital and Related Services for emergency room visits and inpatient hospitalizations; the Consumer Price Index for Professional } \\
\text { Services for home health care, office based visits, dental visits, and outpatient visits; and the Consumer Price Index for Prescription Drugs for prescription drugs. } \\
\text { \| Estimates may not be reliable because they are based on an unweighted sample of fewer than } 30 \text { observations. }\end{array}$} \\
\hline
\end{tabular}

medical events aggregated across all fallers. Separate costs were estimated for inpatient hospital care, emergency room visits, outpatient hospital services, office-based provider visits, dental care, home health care, and prescription drugs. Mean costs per faller and per faller receiving medical care were calculated. Results are presented as estimates for the U.S. noninstitutionalized elderly population.

Our initial estimates assumed that all payments for a fall-related medical event were allocated to the cost of falls. This provided an upper bound for the cost of falls because each medical event could be linked to one or more medical conditions, some of which were fall-related and some of which were not. For example, a medical event that was linked to a fall could also be linked to a nonfall-related condition (such as a stroke, sinus infection, or elevated blood pressure). This could occur whenever more than one medical condition was treated during the same medical event.

Allocating costs in this way may overestimate the costs of falls to the extent that some of the medical events whose costs were attributed fully to falls also treated nonfall-related conditions. To provide a more conservative estimate of the cost of falls, we recalculated the fall-related part of the cost of each fall-related medical event. To do this, we divided the cost of each fallrelated event by the number of conditions linked to it. This figure, rather than the total cost of the event, was then attributed to the cost of falls. We then recalculated the total costs of falls using the revised estimates. This provided a very conservative estimate of fall-related costs. However, making the estimates in this way did provide a lower bound for an estimate of the cost of falls.

Estimates are adjusted for inflation using the Consumer Price Index (CPI) for 2002. This was the latest year for which data were available. The CPI for prescription drugs and medical supplies was used to adjust estimates of prescription drug costs; the professional services component of the CPI was used to adjust estimates for home health care, office-based visits, dental visits, and hospital outpatient visits; the hospital and related services component of the CPI was used to adjust cost estimates for emergency room visits and inpatient hospitalizations.

The number of fall-related deaths and institutionalizations was also examined. However, the unweighted number of these occurrences was too small to allow for reliable estimates. The National Center for Health Statistics suggests that estimates based on fewer than 30 unweighted cases may be unreliable. ${ }^{25}$ The MEPS data included only 19 unweighted deaths and 6 unweighted institutionalizations for all causes among elderly fallers in 1997.

Two additional analyses were done to validate the results of the direct falls cost estimation described above. These analyses included all elderly respondents, both fallers and nonfallers. First, using 1-way analysis of variance, we compared the mean values of total health care costs (both fall and nonfall-related) for fallers and nonfallers. Our assumption was that any difference between total costs of the 2 groups would represent fall-related 
costs. In addition, because total health care costs may be related to demographic characteristics, we used chi-square tests and 1-way analyses of variance to compare the demographics of the groups. The a priori level of significance was $P<0.05$. The variables examined included patient age ( 65 to 74 years, 75 to 84 years, 85 years or older), gender, education (no degree, high school diploma or GED, or bachelor's degree or higher), race/ethnicity (Hispanic, white, or African American), marital status (married or not married), income (defined by the categories "negative or poor," "near poor," "low income," "middle income," and "high income"), and region of the country in which the respondent resided (Northeast, Midwest, South, West).

Finally, we conducted a regression analysis. The dependent variable was total health care expenses (both fall- and nonfallrelated). The primary independent variable was fall status (either reported a fall-related medical condition or did not report a fall-related medical condition). The regression included the demographic variables listed earlier to correct for differences between fallers and nonfallers. The regression coefficient on the fall variable indicated the difference in total health care costs between fallers and nonfallers after adjusting for demographic differences. This provided another estimate of the mean cost per faller. The weighted regression was run using the SURVREG procedure in SAS (SAS Institute, Inc., Cary, North Carolina) ${ }^{26}$ This procedure takes into account the complex survey design used in the MEPS. The a priori level of significance is $P<0.05$.

Virginia Commonwealth University's Institutional Review Board (IRB) determined that the study was exempt from federal regulations requiring IRB review and approval.

\section{Results}

The MEPS file for 1997 included 4,025 elderly (defined as aged 65 years or older) respondents. Of these, 349 respondents (8.7\%, unweighted) reported medical conditions related to 401 falls. The remaining statistics reported in this section are based on weighted analyses that provide estimates for the total U.S. population of noninstitutionalized elderly (defined as aged 65 years or older). This population was estimated to number 34,028,786 on December 31, 1997.

A total of 3,028,562 individuals (weighted $8.9 \%$ of the noninstitutionalized elderly population) reported medical conditions related to 3,407,557 falls for 1997 . Weights were used to estimate population values. Weights differ among individuals in the sample to correct for variance in response rates by age, gender, race/ethnicity, residence in metropolitan statistical area, region of the country, and poverty status. ${ }^{23}$ Fall-related medical care was provided to 2,406,641 individuals (Table 1). This included care for falls occurring both in 1997 and in prior years. The vast majority of fall-related medical conditions were either joint or back disorders, fractures, sprains, contusions, or open wounds (Table 2). A total of 973,177 (24.6\%) fall-related medical conditions were fractures, and 172,462 (4.4\%) were hip fractures.
TABLE 2 Fall-Related Medical Conditions Reported by the Noninstitutionalized Elderly Population of the United States in 1997

\begin{tabular}{|c|c|c|c|}
\hline ICD-9 Code* & Description of Condition & No. Mentions & $\%$ Mentions \\
\hline 959 & Injury (NEC/NOS) & 725,313 & 18.3 \\
\hline 924 & Contusion of leg or other site & 329,425 & 8.3 \\
\hline 719 & Joint disorder (NEC/NOS) & 172,726 & 4.4 \\
\hline 820 & Fracture neck of femur & 172,462 & 4.4 \\
\hline 920 & Contusion of face, neck, or scalp & 155,526 & 3.9 \\
\hline 845 & Sprain of ankle and foot & 138,148 & 3.5 \\
\hline 807 & $\begin{array}{l}\text { Fracture of rib, sternum, larynx, } \\
\text { trachea }\end{array}$ & 128,801 & 3.3 \\
\hline 724 & Back disorder (NEC/NOS) & 119,483 & 3.0 \\
\hline 818 & Fracture arm (MULT/NOS) & 112,931 & 2.9 \\
\hline $\begin{array}{r}810,811,813 \\
815,819,821 \\
823,826,829\end{array}$ & Other types of fractures & 102,623 & 2.6 \\
\hline 873 & Other open wound of head & 92,454 & 2.3 \\
\hline 716 & Arthropies (NEC/NOS) & 85,825 & 2.2 \\
\hline 814 & Carpal fracture & 83,377 & 2.1 \\
\hline 844 & Sprain of wrist and leg & 78,250 & 2.0 \\
\hline 842 & Sprain wrist and hand & 74,440 & 1.9 \\
\hline 729 & Other soft tissue disease & 73,712 & 1.9 \\
\hline 822 & Patella fracture & 70,592 & 1.8 \\
\hline 922 & Contusion of trunk & 67,762 & 1.7 \\
\hline 824 & Ankle Fracture & 65,148 & 1.6 \\
\hline 840 & Sprain shoulder and arm & 60,218 & 1.5 \\
\hline 805 & Vertebral fracture without cord injury & 58,804 & 1.5 \\
\hline $\begin{array}{r}879,881 \\
882,884\end{array}$ & Other open wound & 56,340 & 1.4 \\
\hline 825 & Fracture of tarsal or metatarsal & 51,182 & 1.3 \\
\hline 910-919 & Superficial injury & 51,076 & 1.3 \\
\hline $843,847,848$ & Other sprain & 50,999 & 1.3 \\
\hline 802 & Fracture of face bones & 49,720 & 1.3 \\
\hline 923 & Contusion of upper limb & 45,364 & 1.1 \\
\hline 812 & Humerus fracture & 40,660 & 1.0 \\
\hline 780 & General symptoms & 37,841 & 1.0 \\
\hline \multirow[t]{6}{*}{808} & Pelvic fracture & 36,878 & 0.9 \\
\hline & All other diagnoses & 435,879 & 11.0 \\
\hline & Do not know & 28,651 & 0.7 \\
\hline & Inapplicable & 62,374 & 1.6 \\
\hline & Missing & 43,439 & 1.1 \\
\hline & Total & $3,958,423$ & 100.0 \\
\hline
\end{tabular}

* Total ICD-9 codes are greater than the total number of falls because each fall could result in more than one medical condition.

ICD-9=Intemational Classification of Diseases, 9th Revision; MULT=multiple fractures; $N E C=$ not elsewhere classified (used when there is not a specific code for the patient's condition); NOS =not otherwise specified (used when the coder lacks information necessary to code a more specific four-digit category).

The total direct medical cost of fall-related care in 1997, when allocating all costs of fall-related medical events to the cost of falls, was $\$ 6.2$ billion (Table 1). The 95\% confidence 
TABLE 3 Costs of Fall-Related Medical Care for the Noninstitutionalized Elderly Population of the United States in 1997*

\begin{tabular}{l|r|r|r}
\hline Event & $\begin{array}{c}\text { Total Cost } \\
\text { (1997 Dollars) }\end{array}$ & $\begin{array}{c}\text { Total Cost } \\
\text { (2002 Dollars }{ }^{\ddagger} \text { ) }\end{array}$ & \multicolumn{1}{c}{ \% } \\
\hline Inpatient hospitalizations & $3,336,373,794$ & $4,407,349,782$ & 64.6 \\
Office-based visits & $558,322,692$ & $658,262,454$ & 9.7 \\
Home health care & $557,515,640$ & $657,310,940$ & 9.7 \\
Hospital outpatient visits & $437,421,485$ & $515,719,931$ & 7.6 \\
Emergency room visits & $333,879,529$ & $441,054,858$ & 6.5 \\
Prescription drugs & $60,373,654$ & $76,674,541$ & 1.1 \\
Dental visits & $44,641,634$ & $52,632,486$ & 0.8 \\
Total & $5,328,528,428$ & $6,809,004,991$ & 100.0 \\
\hline
\end{tabular}

* Based on allocating costs of fall-related medical events to the costs of falls by dividing the cost of each fall-related medical event by the number of medical conditions related to the medical event.

† The dental visit estimates may not be reliable because they are based on an unweighted sample of fewer than 30 observations.

\# Estimates were converted to 2002 dollars by multiplying each estimate by the increase in the appropriate Consumer Price Index percentage change from 1997 to 2002 using the Consumer Price Index for Hospital and Related Services for emergency room visits and inpatient hospitalizations; the Consumer Price Index for Professional Services for home health care, office-based visits, dental visits, and outpatient visits; and the Consumer Price Index for Prescription Drugs for prescriptiondrugs.

TABLE $4 \longdiv { \text { Comparison of the Demographic } }$ Characteristics of Noninstitutionalized Elderly Fallers and Nonfallers in 1997*

\begin{tabular}{l|r|r}
\hline Characteristics & Nonfallers (\%) & Fallers (\%) \\
\hline Race/ethnicity & $407(11.9)$ & $26(8.0)$ \\
$\quad$ Hispanic & $465(13.6)$ & $29(9.0)$ \\
African American & $2,548(74.5)$ & $269(83.0)$ \\
$\begin{array}{l}\text { White } \\
\text { Chi-square with } 2 d f=11.5, P=0.003\end{array}$ & \\
\hline Age & $1,999(55.4)$ & $132(37.6)$ \\
65 to 74 years & $1,244(34.5)$ & $150(43.3)$ \\
75 to 84 years & $364(10.1)$ & $67(19.1)$ \\
85 years or older & & \\
Chi-square with $2 d f=49.0, P<0.001$ & $1,850(51.3)$ & $140(40.5)$ \\
\hline Marital status & $1,757(48.7)$ & $206(59.5)$ \\
$\quad$ Married & & \\
Not married & $1,503(41.7)$ & $105(30.3)$ \\
Chi-square with $2 d f=45.7, P<0.001$ & $2,104(59.3)$ & $241(69.7)$ \\
\hline Gender & & \\
Male & & \\
Female & & \\
Chi-square with $2 d f=16.8, P<0.001$ & $753(21.9)$ & $61(18.4)$ \\
\hline Region of the country where patient resides & $768(22.3)$ & $98(29.5)$ \\
Northeast & $1215(35.3)$ & $97(29.2)$ \\
Midwest & $704(20.5)$ & $76(22.9)$ \\
South & & \\
West & & \\
Chi-square with $2 d f=12.6, P=0.005$ & & \\
* The totals for demographic categories differ because of missing data. & \\
$d f=$ degrees of freedom. & & \\
\hline
\end{tabular}

interval (CI) was $\$ 4.6$ to $\$ 7.8$ billion. All costs are reported in 1997 dollars except when otherwise indicated. The mean cost per faller was $\$ 2,039$ (95\% CI, $\$ 1,519$ to $\$ 2,559$ ), and the mean direct medical cost per patient receiving fall-related care was $\$ 2,566$. Expenses were highly skewed. While the mean expense per faller was $\$ 2,039$, the median expense per faller was $\$ 160$; the maximum expense for a faller was $\$ 43,566$. The most heavily utilized services for fall-related care were officebased visits, prescription drugs, and emergency room visits (Table 1). Inpatient hospitalizations, while much less utilized, accounted for more than half of total costs.

When adjusted to 2002 dollars, the total direct medical cost of fall-related care was $\$ 7.8$ billion, the mean cost per faller was $\$ 2,591$, and the mean cost per patient receiving fall-related care was $\$ 3,261$. Our more conservative estimates using the cost of each fall-related medical event divided by the number of medical conditions to which the event was linked indicated total direct medical costs of fall-related care of $\$ 5.3$ billion (Table 3). Mean values were $\$ 1,760$ per faller and $\$ 2,214$ per patient receiving fall-related care.

Univariate analyses indicated no significant associations between fall-related costs and demographic variables of age, gender, education, race/ethnicity, marital status, income, or region of the country in which the respondent resided.

Fallers spent a mean of $\$ 7,411(\mathrm{SD}=\$ 640)$ on total health care expenses in 1997 as compared with $\$ 5,490(\mathrm{SD}=\$ 299)$ for nonfallers. If the difference is attributed to fall-related costs, then fall-related costs would amount to $\$ 1,911$ per faller for the year. The differences could, however, be due to other factors such as demographic differences. As shown in Table 4, fallers were older; more likely to be unmarried, female, and white; and had a different geographic distribution as compared with nonfallers. The groups did not differ significantly on income or education. While univariate analyses indicated no significant associations between fall-related costs and demographic factors, multivariate analyses-which measure the effect of each variable after accounting for the effects of all other variables in the regression-may provide different results.

To control for the effects of the demographic differences, a regression analysis was conducted. The results of the regression of total health care expenses and falls are shown in Table 5. The regression coefficient on the fall variable indicated that total health care expenses for a patient who fell were $\$ 1,672$ higher than the expenses of patients not falling, after correcting for the effects of demographic characteristics.

The distribution of fall-related costs by payer is shown in Table 6 . More than $77 \%$ of total fall-related costs were paid by Medicare and nearly $13 \%$ were paid by private insurance. However, the distribution of costs by payer differed dramatically across services. Nearly $73 \%$ of prescription costs were self-paid by the patient or his family whereas about $89 \%$ of inpatient hospital costs were paid by Medicare. 


\section{Discussion}

The results of our study indicate that fall-related injury affects a large number of the community-dwelling elderly. In 1997 , a total of 3 million individuals $-8.9 \%$ of the noninstitutionalized elderly population-reported a medical condition caused by a fall, and 2.4 million (7.1\%) received medical care for a fallrelated condition.

Previous research has estimated rates of between 4 and 10 injurious falls per 100 community-dwelling elderly persons per year. ${ }^{1,3,4,7}$ Our results are consistent with these estimates. They are at the high end of the range because several of the past studies used more stringent definitions of injury. Tinetti, for example, estimated rates for serious injuries, which were defined as all fractures and dislocations, head injuries resulting in loss of consciousness and hospitalization, joint injuries other than dislocations, and internal injuries resulting in hospitalizations. ${ }^{1}$ Rizzo and Tinetti used similar definitions. ${ }^{3,4}$ Sattin defined a fall injury event as any fall that resulted in "at least one anatomic injury" coded as N800 through N999 in the ICD. ${ }^{7}$ His estimate of 8 injurious falls per 100 elderly per year is close to our estimate.

Our results also indicated that falls result in substantial economic costs for the community-dwelling elderly. The total direct medical costs of treating fall-related injury in this population amounted to $\$ 6.2$ billion in 1997 , and the mean cost per injured faller was $\$ 2,039$. While these estimates are substantial, there is reason to believe that they may be conservative.

Estimates of fall-related costs in past studies are higher than our estimates. Englander estimated that the direct costs of falling in the elderly in the United States were $\$ 17$ billion in 1994 and that the cost per injured elderly faller was $\$ 6,215 .{ }^{18}$ While these estimates are considerably higher than the costs estimated in this study, most of the differences are explained by variations in definitions of cost, estimates of fall rates, populations of interest, and methodologic approach.

Englander's estimates were based on charges for medical services. Our estimates were based on actual reimbursements received by providers. An analysis of the MEPS data indicated that charges were 1.75 times greater than actual reimbursements. Adjusting Englander's estimates by this ratio would yield estimates of direct costs of $\$ 9.7$ billion for the population and of $\$ 3,551$ per faller.

Englander's estimates included the entire elderly population-both community-dwelling and institutionalized. Estimates based on data from the 1995 National Nursing Home Survey indicate that charges of $\$ 6.22$ billion were incurred by elderly patients who were admitted to nursing homes for treatment of fractures in 1994. ${ }^{27}$ (This estimate was made by the authors of the p resent study as follows: A total of 87,500 residents were admitted to nursing homes in the United States in 1994 with a fracture of the neck of the femur and 78,300 were admitted with other fractures. This yields 165,800 residents admitted

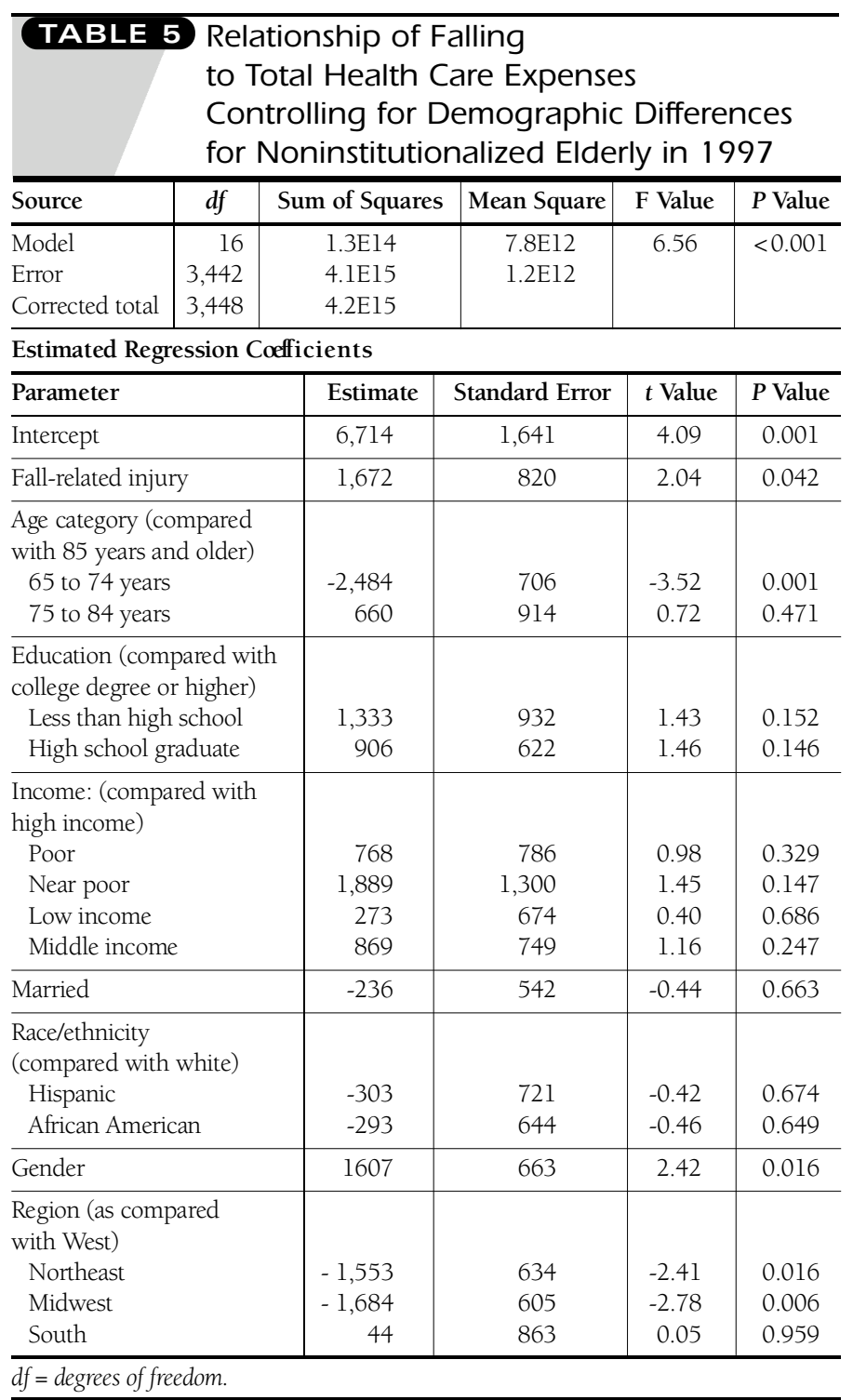

with fractures. This number multiplied by the average nursing home charge per day-\$102.70—and by 365 days per year yields the estimate of $\$ 6.22$ billion.)

Finally, Englander's study was incidence-based. As a result, his estimates included the present value of costs that would be incurred in future years for falls incurred in the year under study. It was not possible to estimate the magnitude of these costs from Englander's estimates. Our study was prevalence-based; it included only costs incurred in the year under study. However, it did include the costs of caring for medical conditions caused by falls in past years.

On the other hand, some of the differences between our study and Englander's would increase the differences between estimates. The estimated number of falls resulting in injury was 
The Cost of Falls Among the Community-Dwelling Elderly

TABLE 6 Distribution by Payer of Fall-Related Costs Incurred by the Noninstitutionalized Elderly Population of the United States in 1997

\begin{tabular}{|c|c|c|c|c|c|c|}
\hline & Self-Paid & Medicare & Medicaid & Private Insurance & Other Sources & Total \\
\hline $\begin{array}{l}\text { Emergency room } \\
\text { Physician (\$) } \\
\% \\
\text { Facility }(\$) \\
\% \\
\text { Total }(\$) \\
\%\end{array}$ & $\begin{array}{r}234,489 \\
0.5 \\
20,911,241 \\
6.4 \\
21,145,731 \\
5.6\end{array}$ & $\begin{array}{r}38,385,828 \\
78.7 \\
170,985,910 \\
52.2 \\
209,371,738 \\
55.6\end{array}$ & $\begin{array}{r}2,783,025 \\
5.7 \\
8,873,532 \\
2.7 \\
11,656,557 \\
3.1\end{array}$ & $\begin{array}{r}4,001,027 \\
8.2 \\
77,799,321 \\
23.7 \\
81,800,347 \\
21.7\end{array}$ & $\begin{array}{r}3,383,928 \\
6.9 \\
49,227,875 \\
15.0 \\
52,611,802 \\
14.0\end{array}$ & $\begin{array}{r}48,788,296 \\
100.0 \\
327,797,879 \\
100.0 \\
376,586,175 \\
100.0\end{array}$ \\
\hline $\begin{array}{l}\text { Inpatient hospital } \\
\text { Physician (\$) } \\
\% \\
\text { Facility (\$) } \\
\% \\
\text { Total (\$) } \\
\%\end{array}$ & $\begin{array}{r}28,422,522 \\
8.1 \\
26,684,709 \\
0.8 \\
55,107,231 \\
1.5\end{array}$ & $\begin{array}{r}214,669,224 \\
61.2 \\
2,957,721,160 \\
91.7 \\
3,172,390,384 \\
88.7\end{array}$ & $\begin{array}{r}7,035,809 \\
2.0 \\
18,288,962 \\
0.6 \\
25,324,771 \\
0.7\end{array}$ & $\begin{array}{r}78,117,219 \\
22.3 \\
222,916,911 \\
6.9 \\
301,034,130 \\
8.4\end{array}$ & $\begin{array}{r}22,314,199 \\
6.4 \\
1,049,170 \\
0.0 \\
23,363,369 \\
0.7\end{array}$ & $\begin{array}{r}350,558,973 \\
100.0 \\
3,226,660,912 \\
100.0 \\
3,577,219,885 \\
100.0\end{array}$ \\
\hline $\begin{array}{l}\text { Home health care }(\$) \\
\%\end{array}$ & $\begin{array}{r}19,414,815 \\
2.0\end{array}$ & $\begin{array}{r}860,908,696 \\
88.5\end{array}$ & $\begin{array}{r}67,714,008 \\
7.0\end{array}$ & $\begin{array}{r}1,287,153 \\
0.1\end{array}$ & $\begin{array}{r}23,358,497 \\
2.4\end{array}$ & $\begin{array}{r}972,683,169 \\
100.0\end{array}$ \\
\hline $\begin{array}{l}\text { Office-based services (\$) } \\
\%\end{array}$ & $\begin{array}{r}47,174,282 \\
7.3\end{array}$ & $\begin{array}{r}313,681,318 \\
48.7\end{array}$ & $\begin{array}{r}20,028,899 \\
3.1\end{array}$ & $\begin{array}{r}188,446,904 \\
29.3\end{array}$ & $\begin{array}{r}74,191,032 \\
11.5\end{array}$ & $\begin{array}{r}643,522,435 \\
100.0\end{array}$ \\
\hline $\begin{array}{l}\text { Dental }(\$) \\
\%\end{array}$ & $\begin{array}{r}34,212,828 \\
76.3\end{array}$ & $\begin{array}{r}10,335,591 \\
23.1 \\
\end{array}$ & $0 . \overline{0}$ & $0 . \overline{0}$ & $\begin{array}{r}276,119 \\
0.6\end{array}$ & $\begin{array}{r}44,824,538 \\
100.0 \\
\end{array}$ \\
\hline $\begin{array}{l}\text { Hospital outpatient services } \\
\text { Facility (\$) } \\
\% \\
\text { Physician (\$) } \\
\% \\
\text { Total (\$) } \\
\%\end{array}$ & $\begin{array}{r}5,480,682 \\
1.6 \\
2,946,260 \\
2.1 \\
8,426,942 \\
1.7\end{array}$ & $\begin{array}{r}121,272,452 \\
35.1 \\
104,799,197 \\
73.1 \\
226,071,649 \\
46.2\end{array}$ & $\begin{array}{r}1,214,965 \\
0.4 \\
- \\
0.0 \\
1,214,965 \\
0.2\end{array}$ & $\begin{array}{r}187,104,233 \\
54.1 \\
4,713,284 \\
3.3 \\
191,817,516 \\
39.2\end{array}$ & $\begin{array}{r}30,490,464 \\
8.8 \\
30,934,043 \\
21.6 \\
61,424,507 \\
12.6\end{array}$ & $\begin{array}{r}345,562,796 \\
100.0 \\
143,392,783 \\
100.0 \\
488,955,579 \\
100.0\end{array}$ \\
\hline $\begin{array}{l}\text { Prescription drugs (\$) } \\
\%\end{array}$ & $\begin{array}{r}51,545,244 \\
72.7\end{array}$ & $\begin{array}{r}3,747,637 \\
5.3 \\
\end{array}$ & $\begin{array}{r}2,233,957 \\
3.2 \\
\end{array}$ & $\begin{array}{r}12,568,165 \\
17.7\end{array}$ & $\begin{array}{r}770,935 \\
1.1 \\
\end{array}$ & $\begin{array}{r}70,865,937 \\
100.0 \\
\end{array}$ \\
\hline $\begin{array}{l}\text { Grand Total (\$) } \\
\%\end{array}$ & $\begin{array}{r}237,027,073 \\
3.8 \\
\end{array}$ & $\begin{array}{r}4,796,507,013 \\
77.7 \\
\end{array}$ & $\begin{array}{r}128,173,157 \\
2.1\end{array}$ & $\begin{array}{r}776,954,215 \\
12.6\end{array}$ & $\begin{array}{r}235,996,261 \\
3.8 \\
\end{array}$ & $\begin{array}{r}6,174,657,718 \\
100.0\end{array}$ \\
\hline
\end{tabular}

20\% lower in Englander's study. His estimates were based on studies conducted in 1982 and adjusted for demographic changes between 1982 and 1994. Because our estimates were based on current (as of 1997) information, they are probably more accurate. Also, Englander's estimates are for 1994 and would have been higher if adjusted to 1997 dollars.

After considering all the differences, Englander may provide higher estimates of the direct medical costs of falls in the community dwelling elderly than did our study. However, the differences are much smaller than they first appear.

Rizzo estimated fall-related costs in 1,017 community dwelling elderly in New Haven, Connecticut, for the period 1989-1991. ${ }^{4}$ Medicare claims data were used to estimate costs for hospitalizations, home health care, emergency room care, and nursing home care. Physician and prescription drug costs were not included. Health care costs of fallers were tracked for one year after the fall and compared with costs for nonfallers during the same time period. Experiencing one noninjurious fall during the year was associated with $\$ 2,500$ (1996 dollars) higher total health care costs compared with nonfallers. Incurring one or more injurious falls was associated with increased health care costs of $\$ 19,440$. These costs are substantially higher than those estimated by either our study or Englander's, and the reason for the differences is not apparent.

The high costs incurred by elderly consumers experiencing noninjurious falls may suggest that falling affects medical conditions that may not appear to be directly fall-related. Because the results in our study were based on consumer self-reports and because our estimates included only services that were directly associated with the fall, this could account for the higher estimates in Rizzo's study. This would also suggest that our study provides a conservative estimate of the cost of falls in the community-dwelling elderly. Fallers may also be frailer than nonfallers, and the higher level of frailty, rather than the falls themselves, may explain the higher health care costs that Rizzo noted among fallers. 
The costs of fall-related injury can be placed in perspective by comparing them with the costs of other common medical conditions. A recent National Institute of Health report warns that "There is considerable variability in the methods and data used to generate $\mathrm{CIO}$ (cost of illness) estimates. As a result, cost estimates for specific diseases, or even for the same disease, may not be comparable."28

However, 2 recent $\mathrm{CIO}$ studies have used the same methods and data sources (MEPS) as the present study and, consequently, are comparable. Comparisons with the estimates provided by these studies indicate that fall-related injury in the communitydwelling elderly is one of the 20 most expensive medical conditions in the United States. In terms of aggregate spending, the $\$ 6.2$ billion spent nationally on fall-related medical conditions is similar to the amounts spent on chronic obstructive pulmonary disease ( $\$ 6.4$ billion), ${ }^{29}$ asthma ( $\$ 5.7$ billion) ${ }^{29}$ and infectious diseases ( $\$ 5.8$ billion). ${ }^{30}$ In terms of mean annual spending per individual, the $\$ 2,039$ spent on treating fall-related medical conditions is comparable to the mean annual amount spent for diabetes ( $\$ 1,978$ per year) and higher than the mean amounts spent for mental disorders $(\$ 1,475)$, osteoarthritis $(\$ 1,014)$, back problems (\$982), and pulmonary conditions (\$699). ${ }^{30}$

While the direct medical costs of fall-related injury are considerable, they underestimate the total burden of fall-related injuryin the elderly. Our estimate of $\$ 6.2$ billion for direct medical costs does not include a number of important costs. We were not able to estimate fall-related direct nonmedical costs, indirect costs, or intangible costs. Direct nonmedical costs include the costs of personal care services and transportation that individuals incur due to disease or disability. Intangible costs include the pain and suffering that result from injury or medical conditions. Both costs are likely to be substantial for elderly patients recovering from the more serious fall-related injuries such as fractures.

Indirect costs are the costs associated with morbidity-related loss of productivity. Indirect costs in the elderly population are minimized to the extent that most elderly are not employed. However, many elderly continue to provide important services to society through such activities as volunteer work, childcare, and caring for friends and relatives. In addition, there may be productivity losses as a result of care provided to injured elderly fallers by family members. Finally, it is important to reiterate that this study only estimated costs for the community-dwelling elderly population. Costs of fall-related care for elderly patients in long-term care facilities were not included.

Our study provides some improvements over past efforts to estimate the cost of falling in the community-dwelling elderly. These improvements include the use of more recent data and calculating the estimates based on a nationally representative sample and a comprehensive set of health services. In addition, our study based cost estimates on actual reimbursement amounts rather than provider charges. This provided a more accurate estimate of actual costs because provider charges are typically higher than actual allowed charges and provider payments.

\section{Limitations}

A major limitation of the study is that it is based on self-report data. P a rticipants in the MEPS survey were asked to recall the medical conditions they suffered over several-month periods and whether those conditions resulted from falls. Accuracy of recall of falls in a general elderly population able to participate in telephone interviews has been studied previously. ${ }^{31}$ The investigators found that between $13 \%$ and $32 \%$ of those suffering a confirmed fall did not recall falling during the specified period of time ( 3 to 12 months). In addition, $28 \%$ of those who experienced a fall resulting in injury did not recall having an injury as a result of the fall at the end of the study period.

There are 2 reasons to believe that recall of falls and fall-related medical conditions was higher in the MEPS. First, MEPS respondents were asked separately about medical conditions and medical events. If either was reported, respondents were asked if the condition or event was fall-related. Thus, respondents may have been better prompted to remember falls. Second, MEPS interviewers suggested that respondents use memory aids such as calendars, receipts, checkbooks, and printouts of medical conditions and care received in prior interview periods. Use of these aids may also have prompted better recall.

\section{Conclusion}

Our results indicated that fall-related medical conditions affected 9\% of the community-dwelling elderly in 1997 and resulted in significant economic costs. Our estimates understate the total economic burden of falls because they do not include direct nonmedical, indirect, and intangible costs of falls and because they exclude falls that occur among the institutionalized elderly. These results highlight the importance of research aimed at decreasing the incidence and severity of falls in the communitydwelling elderly population.

\section{DISCLOSURES}

Funding for this study was provided by Pfizer, Inc., and obtained by authors Norman V. Carroll and Fred M. Cox. Cox is employed by Pfizer, Inc.; Carroll discloses that he has served as a consultant to Pfizer; author Patricia W. Slattum discloses no potential bias or conflict of interest relating to this article. This research was presented, in part, at the 8th Annual International Meeting of the International Society for Pharmacoeconomics and Outcomes Research, Arlington, VA, May 19, 2003. Carroll served as principal author of the study. Study concept and design were contributed by Carroll and Cox. Analysis and interpretation of data and statistical expertise were contributed by Carroll and Slattum. Drafting of the manuscript was primarily the work of Carroll and Slattum, and its critical revision was the work of all authors. 


\section{REFERENCES}

1. Tinetti ME, Doucette J, Claus E, et al. Risk factors for serious injury during falls by older persons in the community. J Am Geriatr Soc. 1995;43:1214-21.

2. Wolinsky FD, Johnson RJ, Fitzgerald JF. Falling, health status, and the use of health services by older adults. A prospective study. Med Care. 1992;30: 587-97.

3. Tinetti ME, Speechley M, Ginter SF. Risk factors for falls among elderly persons living in the community. N Engl J Med. 1988;319:1701-07.

4. Rizzo JA, Friedkin R, Williams CS, et al. Health care utilization and costs in a Medicare population by fall status. Med Care. 1998;36:1174-88.

5. Kiel DP, O'Sullivan P, Teno JM, et al. Health care utilization and functional status in the aged following a fall. Med Care. 1991;29:221-28.

6. Coogler CE, Wolf SL. Falls. In: Hazzard WR, Blass JP, Ettinger WH, Halter JB, Ouslander JG, eds. Principles of Geriatric Medicine and Gerontology. New York: McGraw-Hill; 1999:1535-46.

7. Sattin RW, Lambert HD, DeVito CA, et al. The incidence of fall injury events among the elderly in a defined population. Am J Epidemiol. 1990;131: 1028-37.

8. Covington DL, Maxwell JG, Clancy TV. Hospital resources used to treat the injured elderly at North Carolina trauma centers. J Am Geriatr Soc. 1993;41 $847-52$

9. Tinetti ME, Williams CS. Falls, injuries due to falls, and the risk of admission to a nursing home. N Engl J Med. 1997;337:1279-84

10. Wild D, Nayak SL, Isaacs B. Prognosis of falls in old people at home. J Epidemiol Community Health. 1981;35:200-204

11. Tinetti ME. Preventing falls in elderly persons. N Engl J Med. 2003;348 $42-49$

12. Leipzig RM, Cumming RG, Tinetti ME. Drugs and falls in older people: a systematic review and meta-analysis. I. Psychotropic drugs. J Am Geriatr Soc. 1999:47:30-39.

13. Gillespie LD, Gillespie WJRMC, Lamb SE, et al. Interventions for preventing falls in elderly people. Cochrane Database Syst Rev. 2003; Art. No.: CD000340. DOI: 10.1002/14651858.CD000340.

14. Chang JT, Morton SC, Rubenstein LZ, et al. Interventions for the preven tion of falls in older adults: systematic review and meta-analysis of randomized clinical trials. BMJ. 2004;328:680-86

15. Cumming RG. Intervention strategies and risk-factor modification for falls prevention. A review of recent intervention studies. Clin Geriatr Med. 2002; $18 \cdot 175-89$

16. Keller RB, Slattum PW. Strategies for prevention of medication-related falls in the elderly. Consult Pharm. 2003;18:248-58.
17. Rizzo JA, Baker DI, McAvay G, et al. The cost-effectiveness of a multifactorial targeted prevention program for falls among community elderly persons. Med Care. 1996;34:954-69

18. Englander F, Hodson TJ, Terregrossa RA. Economic dimensions of slip and fall injuries. J Forensic Sci. 1996;41:733-46.

19. Alexander BH, Rivara FP, Wolf ME. The cost and frequency of hospitalization for fall-related injuries in older adults. Am J Public Health. 1992; 82:102023

20. Brainsky A, Glick H, Lydick E, et al. The economic cost of hip fractures in community-dwelling older adults:A prospective study. J Am Geriatr Soc. 1997; 45:281-87.

21. Baron JA, Barrett J, Berger M. Incidence and costs to Medicare of fractures among Medicare beneficiaries aged 65 Years-United States, July 1991-June 1992. MMWR Morb Mortal Wkly Rep. 1996;45:877-83.

22. MEPS HC-0018: 1997 Medical Conditions. Agency for Healthcare Research and Quality. Available at: www.meps.ahrq.gov/pubdoc/hl8doc.pdf. Accessed April 4, 2004.

23. MEPS HC-006C: 1996 Medical Conditions. Agency for Health Care Policy and Research. Available at: www.meps.ahrq.gov/pubdoc/hc6rdoc.pdf. Accessed March 10, 2004

24. MEPS HC-0016: 1997 Office-Based Medical Provider Visits. Agency for Healthcare Research and Quality. Available at: www.meps.ahrq.gov/pubdoc/ hl6doc.pdf. Accessed April 4, 2004.

25. Burt C, Hall M J, Haupt B J, Kozak L J, Ly N, Schappert S. National Health Care Survey, Parts 1 and 2. 2001. Rockville, MD: National Center for Health Services Research. Seminars in Health Services Research Methods: Using Federal and State Databases.

26. SAS 8.02 for Windows. Cary, NC: SAS Institute, Inc.; 2002.

27. Gabrel C, Jones A. The national nursing home survey: 1995 summary. Vital Health Stat. 2000;13:1-45.

28. Disease-specific estimates of direct and indirect costs of illness and NIH support. NIH Available at: wwwl.od.nih.gov/osp/ospp/ecostudies/ COIreportweb.htm. Accessed April 30, 2003.

29. Druss BG, Marcus SC, Olfson M, et al. The most expensive medical conditions in America. Health Aff. 2002;21:105-11.

30. Cohen JW, Krauss NA. Spending and service use among people with the fifteen most costly medical conditions, 1997. Health Aff. 2003;22:129-38.

31. Cummings SR, Nevitt MC, Kidd S. Forgetting falls. The limited accuracy of recall of falls in the elderly. J Am Geriatr Soc. 1988;36:613-16. 